\section{Sarcoidosis in children}

Usually large series of cases of sarcoidosis ${ }^{1-3}$ - such as surveys of defined populations ${ }^{4}$ - have included relatively few children, for the disease most commonly affects adults aged between 20 and 40 . Below the age of 15 most reported cases have been in older children, ${ }^{6}{ }^{7}$ but the true incidence is difficult to assess for two reasons. Firstly, radiography of symptomless individuals, which brings to light many cases in adults, is not a routine procedure in children in most countries. But in Hungary ${ }^{8}$ and Japan, ${ }^{9}$ where such screening is commonplace, cases of symptomless bilateral hilar lymph-node enlargement are found in children just as they are in adults. Secondly, young children with sarcoidosis may present difficult diagnostic problems. Unusual clinical manifestations include chronic polyarthritis ${ }^{10-12}$ possibly mimicking Still's disease, ${ }^{13}$ fever ${ }^{1}$ and abdominal pain, ${ }^{14}$ basal granulomatous meningitis, ${ }^{1516}$ enlargement of the liver and jaundice, ${ }^{17}$ pseudohypertrophic weakness of muscles, ${ }^{18}$ thrombocytopenic purpura, ${ }^{141920}$ and myocardial infiltration. ${ }^{21}$ Furthermore, one of the more easily recognised modes of presentation, Löfgren's syndrome of erythema nodosum with bilateral hilar-node enlargement, seems to be infrequent in children.

Because of the real or apparent rarity in children of sarcoidosis few centres have records of more than a few cases, and hence we know little about prognosis. Reporting a follow-up of 18 children in New York for a mean period of 3.1 years, Siltzbach and Greenberg ${ }^{6}$ found that, as in adults, ${ }^{22}$ prognosis was good for most of those presenting without symptoms. In contrast, all of their patients with symptoms had evidence of extrathoracic sarcoidosis, which correlated with a poorer prognosis. Short-term studies from Japan ${ }^{923}$ have confirmed that most children with symptomless hilar-node enlargement have a favourable outcome. Kendig and Brummer ${ }^{24}$ recently reported the course of 28 children with sarcoidosis diagnosed in Richmond, Virginia, between 1951 and 1974. Twenty were Black and eight White, a relative incidence similar to that in adults in the same area. In only four was the disease found by chest radiography of symptomless children; one of these was examined because two siblings had sarcoidosis and one because of contact with tuberculosis. Of these four, initially symptomless, none developed serious disease. All 28 had abnormal chest radiographs at diagnosis; 27 had bilateral hilar node enlargement, 13 with lung changes, and one lung changes with "doubtful" hilar node enlargement. The most frequent presenting complaint was of tiredness, malaise, and weakness. At the end of the observation period there had been no deaths but five had serious disabilities. Two, both of whom had had uveitis with loss of visual acuity at diagnosis, were "legally blind" and three had severely impaired pulmonary function-a restrictive ventilatory defect with low arterial $\mathrm{Po}_{2}$ and low $\mathrm{PCO}_{2}$. Nine had sarcoid infiltrations of the skin at diagnosis; these included the two who became blind and one of those who developed pulmonary fibrosis: it seems that, as in adults, fixed skin eruptions have poor prognostic implications. ${ }^{22}{ }^{25-27}$ Corticosteroids were used for their suppressive effects and mainly in the management of the more seriously affected patients. As the authors comment, the effect on longterm prognosis is difficult to determine: one patient developed disabling pulmonary fibrosis despite early corticosteroid treatment.

The problems of prognosis in children are similar to those in adults, for it can be based only on assessing the individual case and (as in other chronic diseases) is likely to be more secure after a period of observation. In the absence of symptoms or of evidence of extrathoracic lesions there is a good prospect of spontaneous regression. The chances are reduced in the presence of a fixed skin eruption, or of overt lesions of several organs or tissues; and granulomatous uveitis is a threat to sight. The authors conclude that prognosis in general is better in children than in adults. But, in view of the impossibility of assembling comparable series in the two age-groups, we doubt whether the interesting findings in their small series (though the largest so far reported from a single centre) justify this generalisation.

${ }^{1}$ McGovern, J P, and Merritt, D H, Advances in Pediatrics, 1953, 8, 97.

2 Mayock, R L, et al, American fournal of Medicine, 1963, 35, 67.

${ }^{3}$ Scadding, J G, Sarcoidosis. London, Eyre and Spottiswoode, 1967.

${ }^{4}$ Horwitz, O, Payne, P G, and Wilbek, E, Danish Medical Bulletin, 1967, $14,178$.

${ }^{5}$ British Thoracic and Tuberculosis Association, Tubercle, 1969, 50, 211

6 Siltzbach, L E, and Greenberg, G M, New England fournal of Medicine, 1968, 279, 1239.

7 Kendig, E L, Jr, Pediatrics, 1974, 54, 289.

${ }^{8}$ Mandi, L, Acta Tuberculosa Scandinavica, 1964, 45, 256.

${ }^{9} \mathrm{Miitu}, \mathrm{Y}$, et al, in Proceedings of the VI International Conference on Sarcoidosis, ed K Zwal and Y Hosoda, p 507. Tokyo, University of Tokyo Press, 1974.

10 Burman, M S, and Mayer, L, Archives of Surgery, 1936, 32, 846

11 Zweifel, E, Helvetica Paediatrica Acta, 1946, 1, 476.

12 North, A F, et al, American fournal of Medicine, 1970, 48, 449.

13 Castellanos, A, and Galan, E, American fournal of Diseases of Children, 1946, 71, 513.

${ }_{14}$ Beier, F R, and Lahey, M E, fournal of Pediatrics, 1964, 65, 350.

15 Roos, B, Zeitschrift für Kinderheilkunde, 1937, 59, 280.

16 Naumann, O, Zeitschrift für Kinderheilkunde, 1938, 60, 1.

17 Klatskin, G, and Yesner, R, Yale Fournal of Biology, 1950, 23, 207.

18 Furtado, D, and Carvalho, O, Monatschrift für Psychiatrie und Neurologie, 1947, 114, 54.

19 Cattell, R B, and Wilson, R O, Lahey Clinic Bulletin, 1951, 7, 66.

20 Wright, C S, et al, Blood, 1951, 6, 195.

21 Jonas, A F, Jr, Bulletin of the fohns Hopkins Hospital, 1939, 64, 45.

22 Scadding, J G, British Medical fournal, 1961, 2, 1165.

23 Tachibana, $\mathrm{T}$, et al, in Proceedings of the VI International Conference on Sarcoidosis, ed K Zwal and Y Hosoda, p 503. Tokyo, University of Tokyo Press, 1974

${ }^{24}$ Kendig, E L, Jr, and Brummer, D L, Chest, 1976, 70, 351

25 James, D G, Quarterly fournal of Medicine, 1959, 28, 109.

${ }^{26}$ Sones, M, and Israel, H L, American fournal of Medicine, 1960, 29, 85.

${ }^{27}$ Scadding, J G, Praxis, 1972, 61, 133.

\section{Medical migration and manpower}

At last week's Special Representative Meeting (see p 787) there was genuine concern that many of today's medical students may be unable to find jobs when they graduate. Not only has the NHS come to the end of its fat years of continued growth: already some of our European neighbours-France, Germany, and Denmark-have several hundred doctors out of work, and they find it difficult to understand why Britain is still committed to an expansionist policy. British doctors who hope to find work in Europe will find strong competition there, for, while the Community directives may allow free movement, they do not require a French hospital to employ an English or Scottish doctor in preference to a French one.

Nor will the young men and women still queuing up to enter our medical schools be able to look much outside Europe, apart from the Arab countries. Entry to the USA (except for academic exchange visitors) has been made much more difficult, with a new two-day visa qualifying examination ${ }^{1}$ to be introduced in September 1977; Canada, Australia, and New Zealand no longer have their doors wide open to British graduates. 
Entry to Britain has been tightened, too. The Temporary Registration Assessment Board (TRAB) has just published ${ }^{2}$ the results of its examinations in 1976. Of the 1420 candidates, 506 passed $(36 \%)$, with wide variations in the success rate among doctors of different nationalities. Nigeria and the Sudan had pass rates of about $70 \%$; India and Iraq did better than average; very few candidates from Eastern European and Middle Eastern countries passed. These statistics are not just cold facts: each individual who fails sees the result as a personal tragedy, for-unlike the American ECFMG and the new visa qualifying examinations-the TRAB tests cannot be taken in the candidates' own country. Is there not something wrong with a system which allows so many doctors to come to Britain with unrealistic expectations?

Slowing of medical migration into and out of Britain will have several long-term effects. Until recently most of the foreign graduates who came to Britain worked for the NHS for a few years and then moved on to North America, back to their own countries, or elsewhere. Fewer will do so in future, so that many more of the 10000 or so overseas doctors in junior hospital posts will be looking for career posts in the NHS. For nearly twenty years the pyramidal staffing structure of the hospital service has functioned only because half or more of all senior house officers left the NHS; if they do not then inevitably the system will become clogged.

The end of free medical migration will not, then, solve our manpower problems, as might at first sight appear. If fewer doctors enter and leave Britain each year some of the uncertainties will disappear from the equations, and it should be rather easier to calculate the output of medical graduates required to replace doctors retiring from the NHS. The answer to that calculation seems to be that we need fewer than 2000 new graduates a year, so that we may be training over 1000 doctors a year above our long-term needs. The failure of government and the profession to achieve a rational balance between career and training posts is the primary cause of the current doubts and disputes about manpower. It should now be the top priority on the medicopolitical agenda.

${ }^{1}$ Details from the Educational Commission for Foreign Medical Graduates, 3624 Market St, Philadelphia, Pennsylvania 19104, USA.

2 Temporary Registration Assessment Board, Review of the First Year of the TRAB Tests: Fune 1975-May 1976. London, TRAB, 1977.

\section{Antibiotics over the counter}

Outside Britain-for example, in the United States-preparations containing antibiotics for application to the skin or wounds are available to the public without prescription. In a country where the Food and Drug Administration (FDA) rules other aspects of antibiotic usage with an iron hand this may seem surprising, and three years ago the FDA set up an inquiry to examine whether such preparations were safe and effective. This panel in turn recruited an "industry task force," taken from seven leading pharmaceutical firms, one of which is listed as co-ordinator. Almost the whole of the report ${ }^{1}$ was drafted by three members of the staff of this same company, only one of whom was medically qualified, the others being a bacteriologist and a librarian. This may seem an oddly assorted team to have been entrusted with judgment on a clinical question, but their conclusions were based entirely on a study of published material-and indeed they claim to have read every paper on this subject that has ever been published in the English language. This seems somewhat insular. Granted that Russian and Japanese may be difficult, have authors in France, Germany, and the Latin countries nothing to contribute? Nevertheless, perhaps linguistic convenience was not the main factor: had not the survey been so limited it could not have been completed in the time allowed.

The subject of the inquiry was defined as "the topical use of bacitracin, gramicidin, neomycin, polymyxin B, and the tetracyclines for the prophylactic and therapeutic control of infections in superficial wounds and abrasions of skin." In practice, this definition is far too narrow to include all the uses described in published clinical trials, the review of which occupies a large part of the report. Topical antibiotics are commonly used in the treatment of pyodermas (various, including impetigo), ulcers, and otitis externa and, less frequently, for nasal carriage of staphylococci and infected cardiac pacemakers. The type of preparation most used was a combination such as that of bacitracin, neomycin, and polymyxin. Neomycin gets two chapters to itself by reason of its drawbacks: it may sensitise and staphylococci may become resistant to it. Neomycin also figures largely in a discussion of side effects, though ototoxicity has been reported only after gross misuse-the treatment of extensive burns (from which absorption occurs readily, though not from intact skin) and instillation of large amounts into wounds or body cavities, a type of use quite outside the scope of this inquiry. There are chapters on formulations, the release of antibiotics from the vehicle, and an appendix by Maxwell Finland of Boston provides data on the present sensitivity of bacteria to these antibiotics, generally approving the use of these preparations; he distinguishes between the merits of combinations for local and for parenteral use.

The conclusion of the American survey is that the proper use of these preparations is safe, that they do not interfere with wound healing, and that in general they are effective. Little attempt is made to distinguish their degrees of efficacy for a variety of purposes. One would expect prophylactic application to be more dependable than therapeutic, but even this is not clearly stated. The fallacy in this method of this inquiry (which does not seem to have been recognised) is that it was based entirely on a review of scientific studies, yet its object was to determine the suitability of these products for use by the public. It should surely not be assumed that uninstructed use will have the same effects as professional. Some reassurance may be gained from a short appendix recording that the frequency of complaints of adverse reactions has been only 0.68 and of lack of efficacy not more than 0.28 per million units used. But one should not quarrel with these findings; few experienced people, if any, will dissent seriously from them, unless simply on principle. If instead of setting up this ponderous inquiry the FDA had conducted a poll of some leading surgeons and dermatologists they would have got much the same answer in a much shorter time and with more authority behind it.

\footnotetext{
${ }^{1}$ Anderson, V, International fournal of Dermatology, 1976, 15, suppl to
} No 2 . 